\title{
The Effects of Long-Term Prone Positioning in Patients with Trauma-Induced Adult Respiratory Distress Syndrome
}

\author{
Peter Fridrich, $\mathrm{MD}^{*}$, Peter Krafft, MD*, Hannes Hochleuthner, RNt, and Walter Mauritz, MDt \\ *Department of Anesthesia and General Intensive Care Medicine, Vienna General Hospital, University of Vienna, Vienna, \\ Austria, and +Department of Anesthesia and Critical Care Medicine, Trauma Hospital "Lorenz Böhler," Vienna, Austria
}

\begin{abstract}
Prone positioning improves gas exchange in some patients with adult respiratory distress syndrome (ARDS), but the effects of repeated, long-term prone positioning ( $20 \mathrm{~h}$ duration) have never been evaluated systemically. We therefore investigated 20 patients with ARDS after multiple trauma (Injury Severity Score [ISS] $27.3 \pm 10$, ARDS score $2.84 \pm 0.42$ ). Patients who fulfilled the entry criteria (bilateral diffuse infiltrates, severe hypoxemia, pulmonary artery occlusion pressure $[P A O P]<18 \mathrm{~mm} \mathrm{Hg}$, and $\mathrm{PaO}_{2} /$ fraction of inspired oxygen $\left[\mathrm{FIO}_{2}\right]<200 \mathrm{~mm} \mathrm{Hg}$ at inverse ratio ventilation with positive end-expiratory pressure $[\mathrm{PEEP}]>$ $8 \mathrm{~mm} \mathrm{Hg}$ for more than $24 \mathrm{~h}$ ) were turned to the prone position at noon and were turned back to the supine position at 8:00 AM on the next day. Thus, only two turns per day were necessary, and the risk of disconnecting airways or medical lines was minimized. Prone positioning was repeated for another $20 \mathrm{~h}$ if the patients fulfilled the entry criteria. Except for $\mathrm{FIO}_{2}$, the ventilator settings remained unchanged during the study period. $\Lambda 1$ paticnts were sedated and, if needed, paralyzed to minimize patient discomfort. One hour before and after each position change, ventilator settings and pulmonary and systemic hemodynamics were recorded and blood was obtained for blood gas analysis. Derived
\end{abstract}

cardiopulmonary and ventilatory variables were calculated using standard formulas. Overall mortality was $10 \%$. Oxygenation variables improved significantly each time the patients were placed prone. Immediately after the first turn from the supine to the prone position the following changes were observed: $\mathrm{PaO}_{2}$ increased from $97 \pm 4$ to $152 \pm 15 \mathrm{~mm} \mathrm{Hg}$, intrapulmonary shunt (Qva/Qt) decreased from $30.3 \pm 2.3$ to $25.5 \pm 1.8$, and the alveolar-arterial oxygen difference decreased from $424 \pm 24$ to $339 \pm 25 \mathrm{~mm} \mathrm{Hg}$. All these changes were statistically significant. Most of these improvements were lost when the patients were turned supine, but could be reproduced when prone positioning was repeated after a short period $(4 \mathrm{~h})$ in the supine position. Short periods in the supine position were necessary to allow for nursing care, medical evaluation, and interventions, such as placement of central lines. No position-dependent changes of systemic hemodynamic variables were observed. We conclude that, in trauma patients with ARDS undergoing long-term positioning treatment, lung function improves significantly during prone position compared to short phases of conventional supine position during which the beneficial effects are partly lost.

(Anesth Analg 1996;83:1206-11)
$\mathbf{T}$ he adult respiratory distress syndrome (ARDS) is a serious complication in multiply traumatized patients and a major cause of morbidity and late mortality. Multiple factors including pulmonary edema due to direct lung injury, impaired mucociliary clearance, activation of mediators due to a systemic inflammatory response syndrome, and immobilization may contribute to ARDS.

During ARDS, arterial hypoxemia often may persist despite the administration of large concentrations of

Presented in part at the 5th Vienna Shock Forum, Vienna, Austria, May 8-12, 1995.

Accepted for publication June 27, 1996.

Address correspondence and reprint requests to Walter Mauritz, MD, Department of Anesthesia and Critical Care Medicine, Trauma Hospital "Lorenz Bohler", Donaueschingenstrasse 13, A-1200, Vienna, Austria. inspired oxygen $\left(\mathrm{FrO}_{2}\right)$ and sophisticated techniques of ventilatory support. High $\mathrm{FIO}_{2}$ levels may increase pulmonary venous admixture $(\mathrm{Qva} / \mathrm{Qt})$ by predisposing to pulmonary edema and interstitial pneumonitis and by promoting absorption atelectasis. The use of positive end-expiratory pressure (PEEP), high tidal volumes, and increased peak inspiratory pressure (PIP) to ameliorate hypoxemia is associated with an increased risk of barotrauma and cardiovascular impairment. About $20 \mathrm{yr}$ ago, an improvement in arterial oxygenation was observed during prone (or lateral) positioning of intensive care unit patients (1-3). This change in position may affect pulmonary gas exchange by altering both ventilation and perfusion of the lungs. Several investigators later reported improved oxygenation in patients after prone positioning as well as during kinetic therapy $(4-8)$. The 
long-term effects of repeated turns between supine and prone position, however, have not been investigated.

The goal of this prospective study was to evaluate gas exchange, lung mechanics, and hemodynamic variables in multiply traumatized patients with severe ARDS during repeated, long-term prone positioning of at least $72 \mathrm{~h}$.

\section{Methods}

During the period from July 1, 1992, to December 31, 1994, all patients with trauma-induced ARDS were prospectively studied if they met our study entry criteria (see below). The study was approved by the local ethics committee and informed consent was obtained from the patients' relatives.

ARDS was defined as the presence of acute bilateral diffuse infiltrates on the chest radiograph, severe hypoxemia, and a pulmonary artery occlusion pressure $($ PAOP) $<18 \mathrm{~mm} \mathrm{Hg}$ uncorrected for PEEP.

All patients were receiving mechanical ventilatory support using pressure-limited inverse ratio ventilation with an inspiration/expiration ratio of 2:1, $\mathrm{FIO}_{2}$ (0.8-1.0), respiratory rate (12-22 breaths $/ \mathrm{min})$, and PEEP $(8 \mathrm{~mm} \mathrm{Hg}-14 \mathrm{~mm} \mathrm{Hg}$ ) as required and PIP $<$ $35 \mathrm{~mm} \mathrm{Hg}$ in the supine position. Extracorporeal membrane oxygenation and permissive hypercapnia were not used in the study patients. No specific goals were set for fluid balance; all patients received dopamine $2 \mu \mathrm{g} \cdot \mathrm{kg}^{-1} \cdot \min$, dobutamine, norepinephrine, and normal saline $0.9 \%$ as necessary to maintain cardiac index $(\mathrm{CI})>3.5 \mathrm{~L} \cdot \mathrm{min}^{-1} \cdot \mathrm{m}^{-2}$ mean arterial pressure $>70 \mathrm{~mm} \mathrm{Hg}$, and PAOP $>10 \mathrm{~mm} \mathrm{Hg}$. Colloids were administered if oncotic pressure decreased below $12 \mathrm{~mm} \mathrm{Hg}$, and hemoglobin was maintained at levels of $>10 \mathrm{mg} / \mathrm{dL}$. All patients were sedated; muscle relaxants were used only for short periods of time. Parenteral and enteral nutrition, antibiotic treatment, stress ulcer prophylaxis, and nursing care followed standard protocols. Endotracheal suctioning was performed as required, and a closed suctioning system (Trach Care ${ }^{\mathrm{TM}}$, Ballard, Inc., Midvale, UT) was used in most patients.

Study entry criteria included severe trauma (Injury Severity Score [ISS] > 16), ARDS as defined above; $\mathrm{PaO}_{2} / \mathrm{FIO}_{2}<200 \mathrm{~mm} \mathrm{Hg}$ at inverse ratio ventilation with PEEP $>8 \mathrm{~cm} \mathrm{H}_{2} \mathrm{O}$ for more than $24 \mathrm{~h}$.

Exclusion criteria consisted of intracranial pressure (ICP) $>25 \mathrm{~mm} \mathrm{Hg}$ despite adequate treatment, and unstable cervical spine fractures.

A complete cycle from supine to prone and return to supine was done according to the protocol below: 11:00 AM, evaluation, measurements; $12: 00 \mathrm{AM}$, turn to prone position; and 1:00 PM, measurements. The next day at 7:00 AM, measurements; 8:00 AM, turn to supine position; and 9:00 AM, measurements. Each turn was performed manually by three members of the nursing staff. Usually, the patients stayed in the prone position for $20 \mathrm{~h}$. Earlier turning back to the supine position was permitted in emergencies (e.g., loss of airway or venous access, cardiopulmonary resuscitation) or if the patient did not tolerate the position change. I lead (turned left or right) and arm positions were changed every $2 \mathrm{~h}$. In all patients, air cushion beds (TheraPulse $^{\mathrm{TM}}$ bed, $\mathrm{KCl}$-Mediscus, Inc., San Antonio, TX) were used throughout the study. Chest radiographs were obtained and essential nursing care was delivered during the $4 \mathrm{~h}$ spent in the supine position. During prone positioning the ventilator settings remained unchanged with the exception of the $\mathrm{FIO}_{2}$ which was adjusted to achieve a $\mathrm{PaO}_{2}>80 \mathrm{~mm} \mathrm{Hg}$. Patients were turned prone repeatedly until either recovery or death as long as they met the entry criteria at the evaluation at 11:00 AM.

Before and $60 \mathrm{~min}$ after each turn, arterial and mixed venous blood gases $\left(\mathrm{Po}_{2}, \mathrm{PCO}_{2}, \mathrm{pH}\right.$, lactate), ventilator settings $\left(\mathrm{FIO}_{2}\right.$, tidal volume $\left[\mathrm{V}_{\mathrm{T}}\right]$, PIP, PEEP, inspiration/expiration ratio), and hemodynamic variables (heart rate, mean arterial pressure, mean pulmonary artery pressure, right atrial pressure, pulmonary arterial pressure, PAOP [end-diastolic values], and cardiac output), were recorded. Pressure transducers were zeroed to the midaxillary level. Cardiac output was measured in triplicate by the thermodilution technique using $10 \mathrm{~mL}$ of iced normal saline. Arterial and venous blood gas analyses were performed using an automated blood gas analyzer (Stat-Profile 9, Nova Biomedical, Inc., Waltham, MA). Derived cardiopulmonary and ventilatory variables $(\mathrm{CI}$, pulmonary vascular resistance, oxygen delivery, oxygen consumption, Qva/Qt, alveolar-arterial oxygen difference, $\mathrm{PaO}_{2} / \mathrm{FIO}_{2}$, and static compliance $\left[\mathrm{C}_{\text {stat }}\right]$ ) were calculated using standard formulas.

The prospective data sheets for each turn in each patient were collected together with forms where demographic data [age, sex, cause of trauma, ISS (9), ARDS severity score as described by Murray (10)], duration of treatment, complications, and outcome were recorded. The raw data were manually transferred into a data base (MS Excel ${ }^{\mathrm{TM}}$ ), and the derived variables were calculated automatically. As each patient served as his or her own control the mean values for all variables were compared using analysis of variance (Greulich Software Inc., Staufen, Germany). $P$ values of less than 0.05 were considered to be statistically significant.

\section{Results}

During the 30-mo study period, 31 patients developed severe ARDS and met the entry criteria. Of these, six patients improved rapidly and were turned prone 
Table 1. Clinical Characteristics of the Patients

\begin{tabular}{|c|c|c|c|c|c|c|c|c|c|c|}
\hline \multirow{3}{*}{$\begin{array}{l}\text { Patient } \\
\text { No. }\end{array}$} & \multirow[b]{3}{*}{ Sex } & \multirow{3}{*}{$\begin{array}{l}\text { Age } \\
(\mathrm{yr})\end{array}$} & \multirow[b]{3}{*}{ ISS } & \multirow{3}{*}{$\begin{array}{l}\text { ARDS } \\
\text { score }\end{array}$} & \multirow[b]{3}{*}{ Outcome } & \multirow[b]{3}{*}{ Diagnosis } & \multicolumn{4}{|c|}{ Mechanical ventilation } \\
\hline & & & & & & & \multirow{2}{*}{$\begin{array}{l}\text { Total } \\
\text { days }\end{array}$} & \multicolumn{3}{|c|}{$\begin{array}{l}\text { Days in relation to } \\
\text { prone position }\end{array}$} \\
\hline & & & & & & & & Before & During & After \\
\hline 1 & M & 45 & 25 & 3.0 & $\mathrm{~S}$ & Thoracic trauma & 32 & 7 & 10 & 15 \\
\hline 2 & M & 30 & 29 & 2.5 & $S$ & Head injury, thoracic trauma & 24 & 3 & 16 & 5 \\
\hline 3 & $\mathrm{M}$ & 47 & 22 & 3.0 & $S$ & Head injury, thoracic trauma, multiple fractures & 37 & 4 & 4 & 29 \\
\hline 4 & $\mathrm{M}$ & 54 & 11 & 2.0 & $S$ & Thoracic trauma, multiple fractures & 28 & 2 & 9 & 17 \\
\hline 5 & $\mathrm{~F}$ & 53 & 22 & 2.3 & $S$ & Head injury, thoracic trauma, multiple fractures & 16 & 5 & 5 & 6 \\
\hline 6 & $\mathrm{~F}$ & 19 & $\overline{34}$ & 3.0 & $\mathrm{~S}$ & $\begin{array}{l}\text { Head injury, thoracic trauma, abdominal } \\
\text { trauma, multiple fractures }\end{array}$ & 21 & 11 & 3 & 7 \\
\hline 7 & $\mathrm{M}$ & 55 & 29 & 3.0 & S & Head injury, thoracic trauma, multiple fractures & 13 & 1 & 9 & 3 \\
\hline 8 & $\mathrm{M}$ & 47 & 22 & 2.8 & $S$ & Head injury, thoracic trauma, multiple fractures & 22 & 4 & 12 & 6 \\
\hline 9 & $\mathrm{M}$ & 47 & 22 & 2.8 & $s$ & Head injury, thoracic trauma, multiple fractures & 27 & 1 & 4 & 22 \\
\hline 10 & $\mathrm{M}$ & 54 & 13 & 2.5 & $S$ & Thoracic trauma, multiple fractures, aspiration & 26 & 5 & 4 & 17 \\
\hline 11 & $\mathrm{M}$ & 29 & 34 & 3.3 & S & $\begin{array}{l}\text { Head injury, thoracic trauma, abdominal } \\
\text { trauma, multiple fractures }\end{array}$ & 31 & 9 & 6 & 16 \\
\hline 12 & $\mathrm{M}$ & 32 & 32 & 1.8 & S & Thoracic trauma, abdominal trauma & 20 & 9 & 6 & 5 \\
\hline 13 & M & 58 & 41 & 3.5 & $\mathrm{~S}$ & $\begin{array}{l}\text { Head injury, thoracic trauma, abdominal } \\
\text { trauma, multiple fractures }\end{array}$ & 29 & 2 & 3 & 24 \\
\hline 14 & M & 22 & 32 & 3.0 & $\mathrm{~S}$ & Head injury, thoracic trauma, multiple fractures & 35 & 9 & 14 & 12 \\
\hline 15 & $\mathrm{M}$ & 30 & 48 & 3.0 & $\mathrm{~S}$ & Head injury, thoracic trauma, multiple fractures & 37 & 8 & 12 & 17 \\
\hline 16 & $\mathrm{~F}$ & 72 & 29 & 2.8 & $\mathrm{D}$ & Head injury, multiple fractures & 62 & 13 & 13 & 36 \\
\hline 17 & $\mathbf{F}$ & 62 & 29 & 3.2 & $\mathrm{~S}$ & Head injury, thoracic trauma, multiple fractures & 43 & 10 & 12 & 21 \\
\hline 18 & $\mathrm{M}$ & 55 & 9 & 3.2 & $\mathrm{D}$ & Multiple fractures, sepsis & 19 & 7 & 3 & 9 \\
\hline 19 & $\mathrm{M}$ & 67 & 22 & 3.0 & $S$ & Head injury, thoracic trauma, abdominal trauma & 32 & 5 & 5 & 22 \\
\hline 20 & M & 22 & 41 & 3.0 & $\mathrm{~S}$ & $\begin{array}{l}\text { Head injury, thoracic trauma, multiple fractures, } \\
\text { aspiration }\end{array}$ & 24 & 14 & 4 & 6 \\
\hline $\begin{array}{l}\text { Mean } \\
\pm \text { SEM }\end{array}$ & & 45 & $\begin{array}{r}27.3 \\
\pm 9.7\end{array}$ & $\begin{array}{r}2.84 \\
\pm 0.4\end{array}$ & & & $\begin{array}{r}28.9 \\
\pm 10.6\end{array}$ & $\begin{array}{r}6.45 \\
\pm 3.8\end{array}$ & $\begin{array}{r}7.7 \\
\pm 4.1\end{array}$ & $\begin{array}{r}14.75 \\
\pm 8.8\end{array}$ \\
\hline
\end{tabular}

Patient number, sex, age, ISS (Injury Severity Score) (9), ARDS score [adult respiratory distress syndrome severity score as delineated by Murray (10)], outcome, diagnosis, days of intechanical ventilation (Lolal), and ventilation days before, during, and after prone position of the individual paticnt included in the study. In the "Outcome" column, $\mathrm{S}=$ survived; $\mathrm{D}=$ died.

only once or twice. Three patients were excluded because of increased ICP $(n=2)$ or unstable cervical spine fraclure $(n=1)$ and were treated by kinetic therapy (Roto-Rest ${ }^{\mathrm{TM}}$ bed, KCl-Mediscus, Inc., San Antonio, TX), and two patients received no further treatment because of diagnosis of brain death. Thus, 20 patients were available for final analysis.

Demographic data of these patients are given in Table 1 . Most patients were male $(n=16)$, mean age was $45 \pm 16 \mathrm{yr}$, mean ISS was $27 \pm 10$ and mean ARDS score (10) was $2.8 \pm 0.4$. With one exception (Patient 1 , who had severe thoracic trauma complicated by the aspiration of gastric contents), all patients had sustained multiple blunt trauma (motor vehicle accident or fall) and had required $6.5 \pm 3.8$ days of ventilation until they developed severe ARDS. Five of the patients (24\%) fulfilled the criteria for extracorporeal membrane oxygenation defined by Zapol et al. (11). Mean duration of ventilation was $30 \pm 12$ days with a mean of $8 \pm 4$ days spent in the prone position. ARDS was the only organ failure in 15 patients; 2 patients ( $\mathrm{Pa}$ tients 4 and 18) had renal failure requiring continuous hemofiltration, and 5 patients (Patients 2, 5, 10, 16, 18) had impaired liver function.
A total of 148 cycles were documented; in 11 of these $(7.4 \%)$, the patient was turned back to supine earlier than planned due to emergencies (hemodynamic instability $[n=6]$, nursing requirements $[n=$ 3]), or complications (loss of endotracheal tube $[n=1]$ or of central venous access $[n=1]$ ). Most patients were turned back to prone again after the problems had been managed appropriately. The two complications occurred during the turning maneuver, were treated immediately, and had no deleterious effects. No other complications directly related to the technique were observed. However, two patients developed contractures of either both shoulder and hip joints (Patient 4; 9 days in the prone position) or hip joints (Patient 14, 14 days in the prone position). Both patients had a full functional recovery after prolonged physiotherapy. One patient (Patient 18) developed multiple organ failure due to severe systemic inflammatory response syndrome and died after 19 days, one patient (Patient 16) suffered a cardiac arrest 120 days after transfer to the ward; all other patients survived and were discharged from the hospital.

The results of the first study day are given in Table 2. Oxygenation improved, indicated by signifi- 
Table 2. Ventilation, Oxygenation, and Hemodynamic Variables Throughout the First $24 \mathrm{~h}$ of the Study

\begin{tabular}{lcccc}
\hline & Supine & Prone & Prone & Supine \\
\hline $\mathrm{PaO}_{2} / \mathrm{FIO}_{2}$ & $126.4 \pm 8.6$ & $204.1 \pm 19.2^{*}$ & $247.2 \pm 17.6^{*}$ & $162.4 \pm 14.5$ \\
$\mathrm{PaCO}_{2}$ & $42.3 \pm 1.3$ & $41.5 \pm 1.3$ & $41.0 \pm 1.5$ & $40.6 \pm 1.5$ \\
$\mathrm{Compliance}_{\mathrm{AaDo}}$ & $35.8 \pm 2.4$ & $33.6 \pm 2.1$ & $35.2 \pm 2.6$ & $36.0 \pm 2.4$ \\
$\mathrm{MAP}$ & $424.3 \pm 24.0$ & $338.9 \pm 24.6^{*}$ & $252.7 \pm 25.7^{*}$ & $345.3 \pm 27.3$ \\
$\mathrm{MPAP}$ & $84.4 \pm 3.6$ & $92.4 \pm 3.6$ & $85.0 \pm 4.7$ & $89.0 \pm 2.4$ \\
$\mathrm{CI}$ & $31.8 \pm 1.6$ & $31.7 \pm 1.9$ & $30.3 \pm 1.3$ & $28.4 \pm 1.7$ \\
$\mathrm{Vo}_{2} \mathrm{I}$ & $4.9 \pm 0.2$ & $5.2 \pm 0.2$ & $4.9 \pm 0.2$ & $4.8 \pm 0.2$ \\
$\mathrm{Q}_{\mathrm{va}} / \mathrm{Q}_{\mathrm{t}}$ & $153.2 \pm 13.3$ & $186.2 \pm 13.3^{*}$ & $171.7 \pm 10.6^{*}$ & $172.6 \pm 9.7$ \\
\hline
\end{tabular}

Data are presented as mean \pm SEM.

$\mathrm{FiO}_{2}=$ fraction of inspired oxygen; $\mathrm{AaDo}_{2}=$ alveolar-arterial oxygen difference; $\mathrm{MAP}=$ mean arterial pressure; $\mathrm{MPAP}=$ mean pulmonary artery pressure; $\mathrm{CI}=$ cardiac index; $\mathrm{Vo}_{2} \mathrm{I}=$ oxygen consumption index; $\mathrm{Q}_{\mathrm{va}} / \mathrm{Q}_{\mathrm{t}}=$ pulmonary venous admixture.

$* P<0.05$.

cant increases of $\mathrm{PaO}_{2}$ and $\mathrm{PaO}_{2} / \mathrm{FIO}_{2}$ and significant decreases of alveolar-arterial oxygen difference and Qva/Qt after prone positioning. These beneficial effects were observed immediately after the turn, and there was an additional improvement during the $20 \mathrm{~h}$ in the prone position. When the patients were turned back to the supine position most of these beneficial effects were lost; however, compared to control, the values after the treatment cycle were significantly improved. PIP remained unchanged; $\mathrm{V}_{\mathrm{T}}$, and $\mathrm{C}_{\text {stat }}$ decreased by $10 \%$ immediately after the turn from supine to prone but increased again during the prone positioning. Hemodynamic variables remained virtually unchanged; $\mathrm{CI}$ and oxygen delivery increased immediately after the turn from supine to prone but returned to control values during the following hours.

The long-term effects (four turns, $96 \mathrm{~h}$ ) of prone positioning on some relevant variables of oxygenation and lung function are shown in Figures 1-4. $\mathrm{PaO}_{2} /$ $\mathrm{FIO}_{2}$ (Fig. 1), and Qva/Qt (Fig. 2) show similar patterns: significant improvement after the turn from supine to prone, additional significant improvement during the prone positioning, significant impairment after the turn from prone to supine, and further impairment during the supine positioning. The control values for the second and third cycles, however, are improved compared to the control values for the first cycle. After the first three cycles, however, there is little further improvement, and the additional improvement during the prone positioning is no longer observed. Mean pulmonary artery pressure (Fig. 3) and pulmonary vascular resistance decreased slowly and without consistent relation to the turning maneuvers. $\mathrm{V}_{\mathrm{T}}$ decreased immediately after turning the patient to the prone position followed by a steady increase during the prone positioning. Over the course of $96 \mathrm{~h}$ there was a significant increase in $\mathrm{V}_{\mathrm{T}}$, and this increase was accompanied by a significant increase in the $\mathrm{C}_{\text {stat }}$ (Fig. 4).

With regard to the response to the repeated position changes, the patients could be classified into two

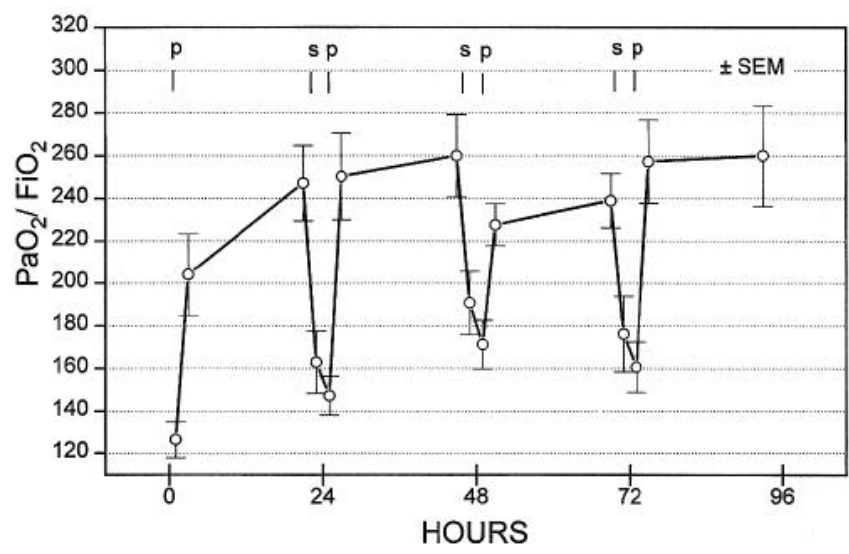

Figure 1. Course of $\mathrm{PaO}_{2} /$ fraction of inspired oxygen $\left(\mathrm{FiO}_{2}\right)$ during the first four study cycles. " $\mathrm{s}$ " and " $\mathrm{p}$ " indicate the points of turning.

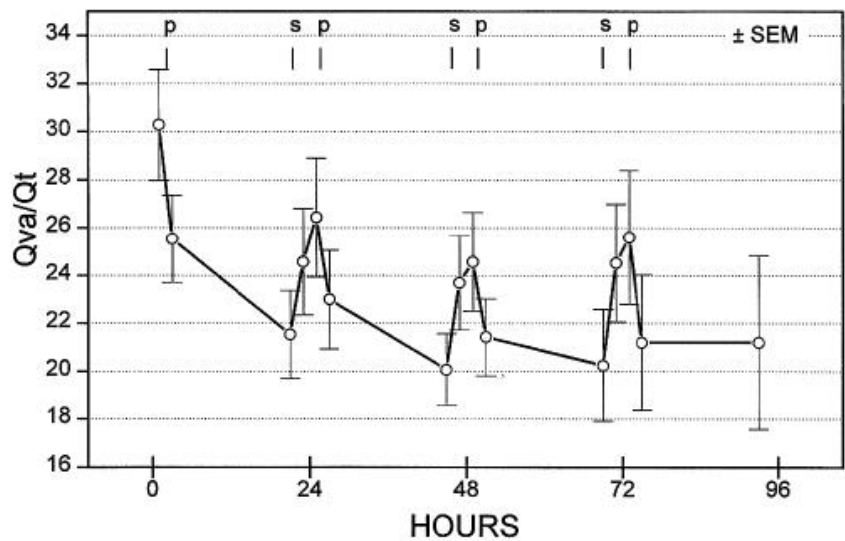

Figure 2. Course of pulmonary venous admixture $(\mathrm{Qva} / \mathrm{Qt}) \mathrm{dur}$ ing the first four study cycles. " $\mathrm{s}$ " and " $\mathrm{p}$ " indicate the points of turning.

groups. Six patients (not included in the final evaluation) required only one or two turns, and 11 patients required three to six turns with a median of four cycles until partial recovery ("fast responders"). Nine patients required more than a week of prone positioning with a median of 12 cycles ("slow responders"). There was no influence of age, sex, ISS, type of trauma, 


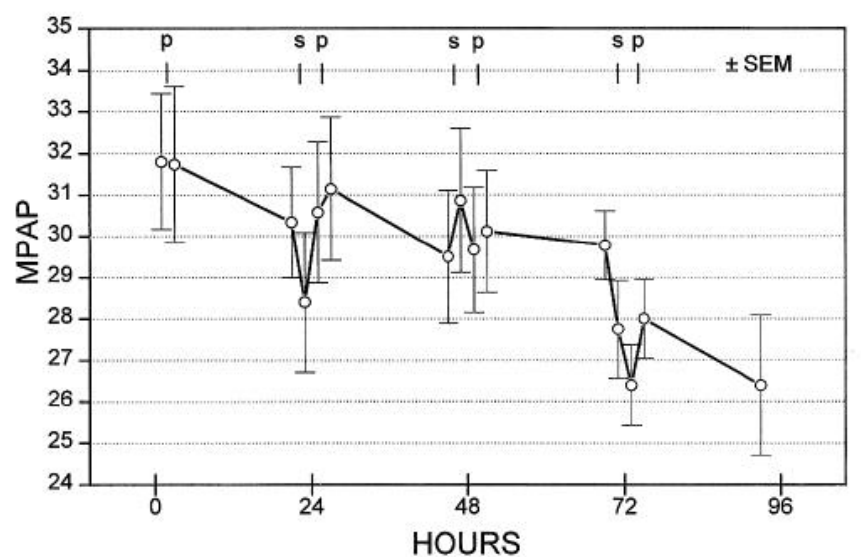

Figure 3. Course of mean pulmonary artery pressure (MPAP) during the first four study cycles. " $\mathrm{s}$ " and " $\mathrm{p}$ " indicate the points of turning.

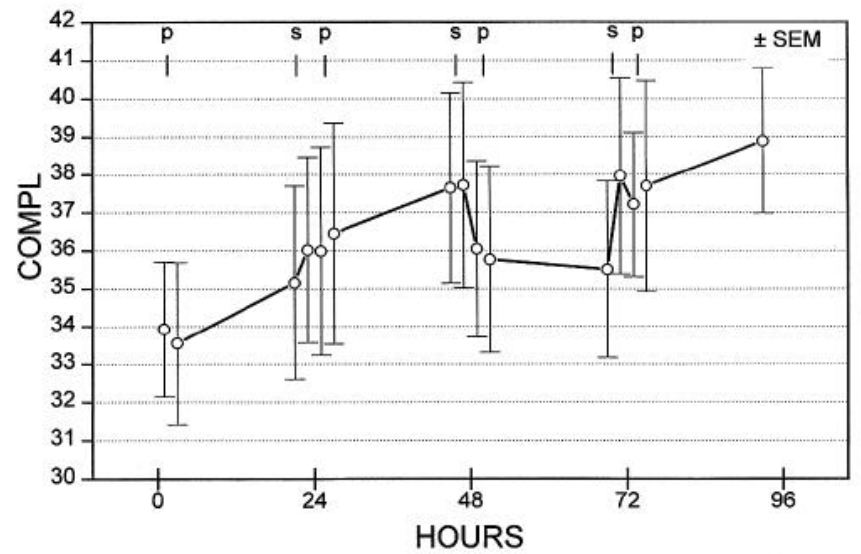

Figure 4. Course of static compliance $\left(\mathrm{C}_{\text {stat }}\right)$ during the first four study cycles. " $\mathrm{s}$ " and " $\mathrm{p}$ " indicate the points of turning.

ARDS score, PEEP levels used, or duration of ventilation before development of ARDS on the required number of days in the prone position. The overall course in those latter patients can be described as follows: significant improvement during turns one to four followed by a "steady state" and a further slow improvement during the last turns. After recovery from the severe ARDS all patients needed conventional ventilation in the supine position (mean $15 \pm$ 9 days).

\section{Discussion}

Our findings confirm previous retrospective reports of gas exchange improvement after prone positioning in patients with moderate to severe respiratory failure. Contrary to other reports $(12,13)$ we found significant improvement in all patients, and this effect was well preserved during repeated cycles of turning. Langer et al. (13) reported that the beneficial effects persisted after turning the patient back to supine, while in our study most of these effects were lost. These differences may be partly explained by the different origin and stage of ARDS in our patients (trauma versus infection; early versus late ARDS); another explanation might be that Langer et al. (13) used higher PEEP levels.

The finding that 11 patients recovered quickly while another 9 patients needed 10 turns or more cannot be explained easily. We were unable to identify any single variable or combination thereof that may have influenced this unexpected observation.

The low mortality $(10 \%)$ in our patients was most likely due to a combination of factors: the patients were relatively young, ARDS was the single organ failure in most patients, ARDS was due to trauma, and the period of ventilation before study entry was only seven days. It is unclear whether prone positioning contributed to the low mortality; Milberg et al. (14) reported a similar outcome for young patients with trauma-induced ARDS. Worse outcome is to be expected with older patients, ARDS of other origin (e.g., sepsis), ARDS in combination with other organ failures, and the occurrence of ARDS during later stages of the underlying disease.

Several mechanisms possibly involved in improvement of oxygenation have been discussed by various authors $(3,12,15-20)$. In the prone position ventilation is redistributed to previously atelectatic areas, and this may be accompanied by redistribution of blood flow (21). In addition, it has been shown that the ventral areas are not adversely affected by prone positioning (20). The overall effects of these changes are a reduction in Qva/Qt and an improvement in the ventilation/perfusion relationship (19). These effects might be most pronounced in early ARDS, and this would explain why all patients in our study were "responders" compared to other studies where up to $40 \%$ of patients did not respond $(13,21)$. This would also explain why most of the beneficial effects were lost after the supine turn in our patients, and why the effects were observed even after repeated turnings. The mechanisms are probably different in late ARDS where lung fibrosis may become the major problem.

We preferred oral over nasal intubation, as the access to the airway is easier in the prone position and there is a lower risk of decubitus ulcers at the nose. One common problem in all patients was the development of facial edema despite regular turning of the head; otherwise, the prone position was well tolerated.

Short periods in the supine position are necessary for nursing, obtaining comparable chest radiographs, and evaluation. Otherwise, there is probably no limitation to the duration of prone positioning. The period of turning is critical (22); at least three experienced nurses are required to avoid losing airway or venous access. The period of 20 hours in the prone position 
was chosen for practical reasons; thus, only two turns per day were necessary in these severely traumatized patients.

An alternative to prone positioning used in many centers is "kinetic therapy" using beds that rotate up to $62^{\circ}$ to the right and left along a horizontal axis $(4,6)$. This option was used in patients who could not be turned because of increased ICP or unstable vertebral fractures. At present there is no study available where prone positioning and kinetic treatment were compared prospectively.

In conclusion prone positioning of ARDS patients has significant immediate effects on oxygenation, but these effects are only partly preserved after the patient is turned back to the supine position. Prone positioning requires an experienced nursing staff, and the periods of turning are critical; however, done properly, severe complications are very rare.

\section{References}

1. Phiel MA, Brown RS. Use of extreme position changes in acute respiratory failure. Crit Care Med 1976;4:13-4.

2. Waganan MJ, Shutaack JG, Moomjiam AS, et al. Improved oxygenation and lung compliance with prone-positioning of neonates. J Pediatr 1979;94:787-91.

3. Douglas WW, Rheder $K$, Frouke MB. Improved oxygenation in patients with acute respiratory failure: the prone position. Am Rev Respir Dis 1974;115:559-66.

4. Fink MP, Helsmoortel CM, Stein KL. The efficacy of an oscillating bed in the prevention of lower respiratory tract infection in critically ill victims of blunt trauma. Chest 1990;97:132-7.

5. Brüssel T, Hachenberg T, Roos N, et al. Mechanical ventilation in the prone position for acute respiratory failure after cardiac surgery. J Cardiothorac Vasc Anesth 1993;7:541-6.

6. Pape IIC, Regel G, Borgmann W, et al. The effect of kinetic positioning on lung function and pulmonary hemodynamics in posttraumatic ARDS: a clinical study. Injury 1994;25:51-7.

7. Hörmann $\mathrm{Ch}$, Benzer $\mathrm{H}$, Baum $\mathrm{M}$, et al. The prone position in ARDS. A successful therapeutic strategy. Anaesthesist 1994;43: $454-62$.
8. Pelosi P, Croci M, Calappi E, et al. The prone positioning during general anesthesia minimally affects respiratory mechanics while improving functional residual capacity and increasing oxygen tension. Anesth Analg 1995;80:955-60.

9. Baker SP, O'Neil B. The injury severity score: an update. J Trauma 1976;16:882-5.

10. Murray JF, Matthay MA, Luce JM, et al. An expanded definition of the adult respiratory distress syndrome (published erratum appears in Am Rev Respir Dis 1988;139:1065). Am Rev Respir Dis 1988;138:720-3.

11. Zapol WM, Snider MT, Hill JD, et al. Extracorporeal membrane oxygenation in severe acute respiratory failure. JAMA 1979;242: 2193-6.

12. Gattinoni L, Pelosi P, Vitale G, et al. Body position changes redistribute lung computed tomographie density in patients with acute respiratory failure. Anesthesiology 1991;74:15-23.

13. Langer M, Mascheroni D, Marcolin R, et al. The prone position in ARDS patients. Chest 1988;94:103-7.

14. Milberg JA, Davis DR, Steinberg KP, et al. Improved survival of patients with acute respiratory distress syndrome (ARDS): 1983-1993. JAMA 1995;273:306-9.

15. Moreno F, Lyons HA. Effects of body posture on lung volumes. J Appl Physiol 1961;16:27-9.

16. Kaneko K, Milic-Emili J, Dolovich B, et al. Regional distribution of ventilation and perfusion as a function of body position. J Appl Physiol 1966;21:767-77.

17. Remolina $\mathrm{C}$, Khan AU, Santiago TV, et al. Positional hypoxemia in unilateral lung disease. N Engl J Med 1981;304:523-6.

18. Gattinoni L, Pelosi P, Valenza F, et al. Patient positioning in acute respiratory failure. In: Tobin MJ, ed. Principles and practice of mechanical ventilation. New York: McGraw Hill, 1994: 1067-76.

19. Beck KC, Vettermann J, Rehder K. Gas exchange in dogs in prone and supine positions. J Appl Physiol 1992;76:2292-7.

20. Lamm WJE, Graham MM, Albert RK. Mechanism by which the prone position improves oxygenation in acute lung injury. Am J Respir Crit Care Med 1994;150:184-93.

21. Pappert D, Rossaint R, Slama K, et al. Influence of positioning on ventilation-perfusion relationships in severe adult respiratory distress syndrome. Chest 1994;106:1511-6.

22. Kollef $\mathrm{MH}$, Schuster DP. The acute respiratory distress syndrome. N Engl J Med 1995;332:27-37. 